\title{
THE EFFICACY OF BUPIVACAINE 0.75 PER CENT AS AN EPIDURAL TEST DOSE
}

\author{
A. Fargas-Babjak, J. McChesney and D.H. Morison
}

ABSTRACT

Two cases are presented in which a test dose of bupivacaine 0.75 per cent was injected before institution of an epidural block, as a safeguard against inadvertent intrathecal injection. In each case there was immediate evidence of motor and sensory blockade, which gave warning that the epidural catheter was positioned in the subarachnoid space. The experience of these two cases indicates that bupivacaine 0.75 per cent would be appropriate for use as a test dose in epidural anaesthesia.

A SMALL TEST DOSE of local anaesthetic is recommended before institution of an epidural block as a safeguard against inadvertent intrathecal injection. ' The use of such of test dose has recently been questioned. ${ }^{2}$ Two cases are reported in which a test dose of bupivacaine 0.75 per cent protected against injection of a large dose of local anaesthetic into the cerebrospinal fluid.

Patient 1. A 33-year-old gravida 4 patient was admitted at term for elective repeat caesarian section under epidural anaesthesia. The epidural block was started with a 17-gauge Tuohy needle at the $\mathrm{L}_{2-3}$ interspace, using a loss-of-resistance technique with saline. A blunt-ended plastic catheter was inserted cephalad into the epidural space and no fluid was obtained on aspiration. Three $\mathrm{ml}$ of bupivacaine 0.75 per cent were injected and the patient was then positioned with a left lateral tilt. She immediately complained of inability to move her legs, associated with numbness and tingling. Systolic blood pressure fell to $90 \mathrm{~mm} \mathrm{Hg}$, but increased to $110 \mathrm{~mm} \mathrm{Hg}$ after ephedrine $10 \mathrm{mg}$ given intravenously, as well as a fluid challenge. Since she was analgesic to the level of $T_{1}$, the operation was done and a healthy male infant was delivered.

During the course of the operation clear fluid could be withdrawn easily from the epidural catheter. Sensation and full motor power returned to her legs $2.5 \mathrm{hrs}$ after the bupivacaine injection. The postoperative course was uneventful and she did not develop a headache.

Patient 2. A 26-year-old secundigravida was scheduled for a repeat caesarean section under epidural anaesthesia. A technique similar to that in the previous case was used for insertion of the epidural catheter. Upon injection of a test dose of

A. Fargas-Babjak, M.D., F.R.C.P.(C), J. McChesney, M.B.Ch.B., D.H. Morison, M.B.Ch.B., F.R.C.P.(C). McMaster University Medical Centre, Box 2000. Station "A", Hamilton, Ontario, L8N $3 Z 5$. 500
$1.5 \mathrm{ml}$ of bupivacaine 0.75 per cent the patient immediately noticed tingling in both feet and this raised the suspicion that the catheter was in the subarachnoid space. A steady flow of clear fluid was aspirated from the catheter. An additional $3 \mathrm{ml}$ of bupivacaine 0.75 per cent was injected, producing analgesia to the level of $\mathrm{T}_{4}$. Initially the systolic blood pressure decreased from $110 \mathrm{~mm}$ $\mathrm{Hg}$ after the bupivacaine injection but increased to $100 \mathrm{~mm} \mathrm{Hg}$ with the intravenous administration of ephedrine $20 \mathrm{mg}$ given in increments. The operation was uneventful and a healthy male infant was born. Postoperative recovery was unremarkable apart from a mild headache on the first postoperative day, which was controlled by analgesics.

\section{Discussion}

These two cases illustrate the use of bupivacaine 0.75 per cent as a test dose for epidural block. In the first case, the test dose of $3 \mathrm{ml}$ of bupivacaine 0.75 per cent produced a sensory level of $T_{1}$, which was adequate for the caesarean section to the done. In the second case, while $1.5 \mathrm{ml}$ produced immediate sensory loss, raising the suspicion of intrathecal injection, supplementation by a further $3 \mathrm{ml}$ was required to provide adequate anaesthesia for the operation. In each case the possibility of the epidural catheter being in the cerebrospinal fluid was raised because of the rapid onset of sensory and motor block within two minutes after the injection of the test dose. This was subsequently confirmed by withdrawal of clear fluid through the catheter.

In each of these two cases the use of a test dose avoided the administration of a large volume of local anaesthetic which would probably have resulted in a total spinal block.

Cases have been reported in which the injec- 
tion of a test dose of other local anaesthetic solutions has not prevented the subsequent injection of a larger volume, thus producing a total spinal block. ${ }^{3-5}$ These reports have tended to reduce the value of a test dose.

The injection of a small volume of bupivacaine 0.75 per cent as a test dose in these two cases produced clear evidence that the tip of the epidural catheter was positioned within the cerebrospinal fluid, because of the rapid onset and the level of anaesthesia that ensued. Therefore bupivacaine 0.75 per cent would appear to be an appropriate local anaesthetic solution for use as an epidural test dose.

\section{REFERENCES}

1. Bromage, P.R. Epidural analgesia, 1st ed.. Philadelphia: Saunders (1978).

2. Scotr, D.B. Analgesia in labour. Br. J. Anaesth. 49: $11(1977)$

3. Gillies, I.D.S. \& Morgan, M. Accidental total spinal analgesia with Bupivacaine. Anaesthesia 28 : 441 (1973).

4. BoYs, J.E. \& Norman, P.F. Accidental subdural analgesia. Br. J. Anaesth. 47: 1111 (1975).

5. Mayсоск. E. An epidural anaesthetic with unusual complications. Anaesth. Intens. Care 6:263 (1978).

RÉSUMÉ

Les auteurs rapportent deux cas où une injection-test de bupivacaïne à 0.75 pour cent avant l'administration de la dose prévue pour une anesthésie péridurale a permis de prévenir une injection sous-arachnoidienne accidentelle. Dans les deux cas, on a observé un bloc moteur et sensitif immédiatement après l'administration de la dose-test, indiquant que le cathéter péridural était de fait dans l'espace sous-arachnoìdien. Une concentration de 0.75 pour cent de bupivacaine est donc adéquate comme agent-test dans les cas d'anesthésie péridurale. 